\section{Akinetoplastic Strain of Trypanosoma evansi produced by 'Prothidium'}

Since Werbitzki's ${ }^{1}$ observations that organic dyes having Ehrlich's orthoquinoid constitution caused disappearance of the kinetoplast in trypanosomes, several workers have, from time to time, reported the occurrence of both spontaneous and chemically induced strains of akinetoplastic T. evansi. Hoare ${ }^{2}$ has fully discussed the early literature on the subject. Recently, Muhlpfordt ${ }^{3}$ has published his observations on the effect of trypaflavin on the kinetoplast of various trypanosomes, and has shown that repeated administration of trypaflavin caused the complete disappearance of kinetoplast in $T$. evansi in 81 days. With other trypanosomes such as $T$. equiperdum, $T$. bruce $i$ and $T$. gambiense it took 54,121 and 122 days, respectively, for the complete disappearance of this organelle.

Hoare and Bennett ${ }^{4}$ in 1938 showed that both spontaneous and induced akinetoplastic strains of $T$. evansi behaved like the normal ones, and that the absence of kinetoplast did not in any way alter the vital functions of the trypanosomes.

We have observed: (1) the quick disappearance of the kinetoplast from the otherwise normal strain of $T$. evansi as a result of treatment with a phenanthridinium compound 'Prothidium'; and (2) some apparent change in the functional activity of the akinetoplastic 'Prothidium'-treated strain.

The chemical composition of 'Prothidium' (Boots) is 2-amino-7-(2-amino-6-methyl-4 pyrimidylamino)-9amino-phenyl-phenanthridine $: 10: 1$-dimetho-bromide. $0.5 \mathrm{ml}$. of a freshly made 0.015 per cent solution of this drug was given subcutaneously to white rats weighing 100-125 gm, and showing a fair number of trypanosomes in the peripheral circulation. Three sets of experiments were carried out with two rats in each set. The ratio of kinetoplastic to akinetoplastic trypanosomes was estimated by counting a hundred trypanosomes in a stained smear made from one of the rats in each series. The akinetoplastic 'Prothidium'-treated strain is now being maintained in this laboratory and its functional behaviour so far observed (up to its 8th passage in rats) is reported as follows.

From Table 1 it will be seen that there was complete disappearance of the kinetoplast 44-60 hr. after treatment with the drug.

Table 1. Percentage of Kinetoplastic $(K)$ and Alineroplastic ( $A K$ ) TRYPANOSOMES AT DIFHERENT HOURS

\begin{tabular}{|c|c|c|c|}
\hline & $18 \mathrm{hr}$. & $44 \mathrm{hr}$. & $60 \mathrm{hr}$. \\
\hline $\begin{array}{l}\text { Series I } \\
\text { Series II } \\
\text { Series III }\end{array}$ & $\begin{array}{l}K .28: A K 72 \\
K .42: A k \\
K .34: A K 66\end{array}$ & $\begin{array}{c}\text { All akinetoplastic } \\
K .17: A K 88 \\
K .20: A K 80\end{array}$ & $\begin{array}{l}\text { All akinetoplastic } \\
\text { trypanosomes } \\
\text { disappeared* }\end{array}$ \\
\hline
\end{tabular}

- There was a relapse after 30 days when only $A K$ forms were seen.

The akinetoplastic strain thus obtained was found to breed true when passaged through rats. Table 2 shows an alteration in the functional activity of the akinetoplastic 'Prothidium'-treated strain as compared to the normal.

From Table 2 it is apparent that the akinetoplastic trypanosomes multiply less rapidly than the normal strain, and this leads to longer survival after infection. Ultimately, however, the host succumbs to infection with the same clinical and pathological picture as seen in rats infected with a normal strain of $T$. evansi. This
Table 2. Prepatent and Survivax PeRiods of Rats InFected with NORYAL AND 'PROTHIDIUM'-TREATED STRAIN OF $T$, evansi Normal strain 'Prothidium'-treated strain Tncubation period in
days in six rats Survival time in days $2,2,2,2,3,3 \quad 5,5,6,9,12,12$ of trypanosomes

akinetoplastic strain is now in its 8th passage, and the results are awaited with regard to its course of infection in larger animals (dog and horse).

H. N. RAY

M. N. Malfotra

Department of Protozoology,

School of Tropical Medicine, Calcutta.

${ }^{1}$ Werbitzki, F. W., Centralbl. Bakt., Abt. I. Orig., 53, 303 (1910). ${ }^{2}$ Hoare, C. A., J. Protozool., 1, 28 (1954).

${ }^{3}$ Muhlpfordt, H., Z. Tropenmed. u. Parasit, 10, 19 (1959).

"Hoare, C. A., and Bennett, S. C. J., Parasitol., 30, 529 (1938).

\section{Studies on Phycobilin Formation with Mutants of Cyanidium caldarium}

VARIOUSLY pigmented mutants of Cyanidium caldarium, an organism classified in succession as a blue-green, green, and red alga by Hirose ${ }^{1}$ and which Allen ${ }^{2}$ regards as an anomalously pigmented chloro. phyte, appear to be excellent experimental materials for study of the synthesis of phycocyanin.

Pigment analysis of light-grown wild-type $C$. caldarium confirmed Allen's ${ }^{2}$ report of the presence of chlorophyll $a$, carotenoid, and phycocyanin in this organism. In addition, allophycocyanin was found to be present. Absorption spectra of the extracted pigments are shown in Fig. 1. Dark-grown wild-type cells, unlike those reported by Allen ${ }^{2}$, have been found to yield measurable amounts of chlorophyll $a$ as well as carotenoid. As in the work reported by Allen $^{2}$ no phycobilins have been found in darkgrown wild-type cells. Mutant forms were obtained by exposure of wild-type or mutant cells to ultraviolet light. Absorption spectra of whole-cell suspensions of the wild and mutant types are shown in Fig. 2. Solutions of individual pigments were obtained as follows: (a) Cells were broken by grinding with polishing alumina or by means of a $10 \mathrm{kc} . / \mathrm{s}$. Raytheon sonic oscillator. (b) The chlorophyll and carotenoid pigments were then extracted in methanol and petroleum ether and separated on a sugar column developed with petroleum ether and $n$-propanol after the method described by Strain ${ }^{3}$. (c) The water-soluble phycobilins were separated on a calcium phosphate column ${ }^{4}$ developed with $0.06 \mathrm{M}$ sodium phosphate. Absorption spectra of extracted pigments and whole-cell suspensions were determined with a Cary recording spectrophotometer, model No. 11. The opal glass procedure of Shibata et al. ${ }^{5}$ was used for the determination of absorption spectra of suspensions of intact cells. The organisms were grown at room temperature or at $43^{\circ} \mathrm{C}$. on a medium similar to that used by Allen ${ }^{2}$, to which 1 per cent gluoose was added.

Four general types of variant forms have been found.

(1) Dark-greening mutants. Cultures of wild-type cells grown in darkness are yellow; carotenoid and traces of chlorophyll are detectable spectrophoto. 